\title{
Polymorphism rs547984 on human chromosome 1q43 is not associated with primary open angle glaucoma in a Saudi cohort
}

Taif A. Azad ${ }^{1}$, Nikhil B. Edward², Altaf A. Kondkar ${ }^{1}$, Hatem Kalantan', Saleh Altuwaijri ${ }^{3,4}$, Tahira Sultan', Faisal A. Al-Mobarak', Saleh A. Al-Obeidan ${ }^{1}$ and Khaled K. Abu-Amero ${ }^{1,5,6^{*}}$

\begin{abstract}
Background: To investigate the association between polymorphism rs547984, located in close proximity to the Zona Pellucida Glycoprotein 4 (ZP4) gene on human chromosome 1q43 and primary open angle glaucoma (POAG).

Method: Polymorphism rs547984 was genotyped using Taq-Man ${ }^{\circledR}$ assay in 185 subjects comprising of 90 unrelated POAG cases and 95 controls of Saudi origin.

Results: Association analysis between cases and controls revealed no significant genotype distribution under additive $(p=0.356)$, dominant $(p=0.517)$ and recessive $(p=0.309)$ models. Besides, the allele frequency distribution was also found to be non-significant $(p=0.70)$. The minor " $A$ " allele frequency was found to be 0.49 and 0.50 among POAG cases and controls, respectively. In addition, specific clinical indices used to assess severity of glaucoma such as intraocular pressure (IOP), cup/disc ratio and number of anti-glaucoma medication also did not show any significant genotype distribution in POAG cases.
\end{abstract}

Conclusion: Polymorphism rs547984 is neither associated with any clinical indices important for POAG such as IOP and cup/disc ratio nor is a risk factor for POAG in the Saudi cohort.

Keywords: Poag, r5547984, Saudi, ZP4

\section{Background}

Primary open angle glaucoma (POAG) is the second most common form of glaucoma in Saudi Arabia and a leading cause of irreversible blindness worldwide [1]. POAG is known to have a genetic component with twoto four-fold risk of POAG in first-degree relatives as compared to the general population. However, due to the polygenic nature of POAG with genetically complex and multifactorial inheritance its exact genetic etiology is still unknown [2].

\footnotetext{
* Correspondence: abuamero@gmail.com

'Glaucoma Research Chair, Department of Ophthalmology, College of

Medicine, King Saud University, Riyadh 11411, Saudi Arabia

${ }^{5}$ Department of Ophthalmology and Visual Sciences, University of Illinois at Chicago, Chicago, IL, USA

Full list of author information is available at the end of the article
}

Recently, using population-based genome wide association study (GWAS), several investigators have identified a number of variants in multiple loci/genes to be associated with POAG and related quantitative traits that may contribute to the development and/or progression of the disease in various ethnic groups [3]. Nakano et al. described the first GWAS in in a group of Japanese POAG patients and identified 3 genetic loci consisting of six single nucleotide polymorphisms (SNPs) to be associated with POAG. Of these, 4 intergenic SNPs including rs547984, located on human chromosome 1q43 flanking the Zona Pellucida Glycoprotein 4 (ZP4) gene were found to be in strong linkage [4]. ZP4 gene is involved in functions related to fertilization and preimplantation development and thus far SNPs and/or mutations in this gene were reported in association with ovarian diseases 
[5] and POAG [4]. However, subsequent studies have failed to replicate this association between rs547984 and POAG in a South Indian [6], Afro-Caribbean [7], Japanese [8] and Korean [9] population. Besides, the functional relevance of the SNP or the gene to POAG development is not known.

Despite a high prevalence of POAG in Saudi population the role of genetic polymorphisms in the development of the disease is still unclear [3]. Our previous attempts to identify genetic associations between POAG and polymorphisms in genes including caveolin (CAV1/ $C A V 2)$ [10], atonal homolog 7 (ATOH7) [11], cyclindependent kinase inhibitor 2B (CDKN2B) [12], and transmembrane and coiled-coil domain 1(TMCO1) [13] did not yield any positive results indicating that the genetic cause for POAG in patients of Saudi origin may be different than those from European descent. In addition, there are no reports of association of polymorphisms in ZP4 gene in the middle-eastern POAG patients. With the aim to identify a genetic link and provide further validation of this POAG-associated variant in a different ethnic group, we investigated whether SNP rs547984 is associated with POAG in the middleeastern cohort of Saudi Arabia.

\section{Methods}

\section{Study design and population}

The study adhered to the tenets of the Declaration of Helsinki and all participants signed an informed consent. The study was approved by the College of Medicine ethical committee (approval number \# 08-657). To perform a case-control study Saudi patients with a clinically confirmed diagnosis of POAG and a matching group of glaucoma free healthy controls were recruited into the study at King Abdul-Aziz University Hospital (KAUH) in Riyadh, Saudi Arabia. A total of 185 subjects comprised of 90 POAG patients and 95 controls of Saudi origin were included in this study. POAG patients satisfied the following strict clinical criteria for inclusion: i) appearance of the disc or retinal nerve fibre layer e.g. thinning or notching of disc rim, progressive changes, nerve fibre layer defect; ii) the presence of characteristic abnormalities in the visual field (e.g. arcuate scotoma, nasal step, paracentral scotoma, generalized depression) in the absence of other causes or explanation; iii) age greater than 20 years at the time of recruitment and iv) open anterior chamber angles bilaterally on gonioscopy. Exclusion criteria included evidence of secondary glaucoma, e.g. pigmentary glaucoma, uveitic, pseudoexfoliation, or any other form of secondary glaucoma, and history of steroid use or ocular trauma. Healthy controls free from glaucoma by examination were recruited. Inclusion criteria for controls were age $>20$ years, normal intraocular pressure (IOP) $[\mathrm{IOP}<21 \mathrm{mmHg}$ without any anti-glaucoma medication], open angles on gonioscopy, and normal optic disc on examination.

\section{DNA preparation}

DNA samples were obtained from peripheral blood $(7 \mathrm{~mL})$ collected in EDTA tubes from all participating individuals. Extraction was performed using the illustra blood genomicPrep Mini Spin kit (GE Healthcare, Buckinghamshire, UK) and stored at $-20{ }^{\circ} \mathrm{C}$ in aliquots until further use. Quantification of extracted DNA was performed using a NanoDrop ND-2000c spectrophotometer (Thermo Scientific, Wilmington, DE, USA).

Genotyping of rs547984 at Chr.1: 237,933,586 on GRCh38 Subjects were genotyped for polymorphism rs547984 using the TaqMan ${ }^{\circ}$ SNP Genotyping Assay (Applied Biosystems Inc., Foster City, CA, USA) on ABI 7500 RealTime PCR System (Applied Biosystems) as described previously [14]. For detection of rs547984 polymorphisms, assay IDs: C_8859642_10 was used. A $25 \mu \mathrm{L}$ PCR reaction consisted of $1 \mathrm{X}$ TaqMan $^{\circ}$ Genotyping Master Mix (Applied Biosystems), 1X SNP Genotyping Assay Mix and 20 ng DNA. Each 96-well plate included two no template controls. Real-time PCR was performed on an ABI 7500 using the recommended conditions consisting of incubation at $95{ }^{\circ} \mathrm{C}$ for $10 \mathrm{~min}$, followed by 40 cycles, denaturation at $92{ }^{\circ} \mathrm{C}$ for $15 \mathrm{~s}$ and annealing/extension at $60{ }^{\circ} \mathrm{C}$ for $1 \mathrm{~min}$. The $\mathrm{VIC}^{\circ}$ and 6-carboxy-fluorescein (FAM) fluorescence levels of the PCR products were measured at $60{ }^{\circ} \mathrm{C}$ for $1 \mathrm{~min}$. Analysis of fluorescence using the automated 2-color allele discrimination software on ABI 7500

Table 1 Demographic and clinical characteristics of POAG cases and controls

\begin{tabular}{|c|c|c|c|}
\hline Variables & $\begin{array}{c}\text { Controls }(n=95) \\
\text { No. }(\%)\end{array}$ & $\begin{array}{c}\text { Cases }(n=90) \\
\text { No. }(\%)\end{array}$ & $p$ value $^{a}$ \\
\hline \multicolumn{4}{|l|}{ Demographic Characteristics } \\
\hline Age in years, mean $( \pm S D)$ & $57.1(13.5)$ & $60.7(12.3)$ & $0.061^{b}$ \\
\hline Male & $69(72.6)$ & $55(61.1)$ & 0.096 \\
\hline Female & $26(27.3)$ & $35(38.8)$ & - \\
\hline \multicolumn{4}{|l|}{ Systemic Diseases } \\
\hline Diabetes mellitus & $45(47.3)$ & $49(54.4)$ & 0.334 \\
\hline Coronary artery disease & $6(6.3)$ & $6(66.6)$ & 0.920 \\
\hline Hypertension & $44(46.3)$ & $47(52.2)$ & 0.420 \\
\hline Hypercholesterolemia & $9(9.4)$ & $14(15.5)$ & 0.210 \\
\hline \multicolumn{4}{|l|}{ Health Awareness/Behavior } \\
\hline \multicolumn{4}{|l|}{ Family history of glaucoma } \\
\hline Smoking & $41(43.1)$ & $34(37.7)$ & 0.458 \\
\hline
\end{tabular}

${ }^{\mathrm{a}}$ Chi ${ }^{2}$ test, ${ }^{\mathrm{b}}$-test 
Table 2 Association analysis of SNP rs547984 with allele frequency and genotype distribution in POAG patients and controls

\begin{tabular}{|c|c|c|c|c|c|}
\hline \multirow{2}{*}{$\begin{array}{l}\text { SNP (Nearest gene) } \\
\text { Allelic analysis }\end{array}$} & \multicolumn{5}{|c|}{ rs547984 (ZP4) } \\
\hline & Controls $(n=95)$ No. (\%) & POAG $(n=90)$ No. $(\%)$ & Odds ratio & 95\% confidence interval & $p$ value $^{a}$ \\
\hline C & $95(50.0)$ & $92(51.1)$ & 1 & Reference & - \\
\hline$A^{b}$ & $95(50.0)$ & $88(48.9)$ & 1.08 & $0.72-1.62$ & 0.708 \\
\hline HWE P & 0.60 & 0.13 & - & - & - \\
\hline \multicolumn{6}{|c|}{ Genotype and Model analysis } \\
\hline $\mathrm{C} / \mathrm{C}$ & $25(26.3)$ & $20(22.2)$ & 1 & Reference & - \\
\hline $\mathrm{C} / \mathrm{A}$ & $45(47.3)$ & $52(57.7)$ & 0.69 & $0.34-1.41$ & 0.310 \\
\hline $\mathrm{A} / \mathrm{A}$ & $25(26.3)$ & $18(20.0)$ & 1.11 & $0.47-2.58$ & 0.806 \\
\hline Additive (Trend) & - & - & - & - & $0.356^{c}$ \\
\hline Dominant & - & - & 1.25 & $0.63-2.45$ & 0.517 \\
\hline Recessive & - & - & 0.70 & $0.35-1.39$ & 0.309 \\
\hline
\end{tabular}

${ }^{\mathrm{a}}$ Chi ${ }^{2}$ test, ${ }^{\mathrm{b}}$ Risk variant, HWE P - Hardy-Weinberg equilibrium $p$ value, ${ }^{\mathrm{c}}$ Fisher exact test

showed clear discrimination of both the genotypes on a two-dimensional graph.

\section{Statistical analysis}

Data was presented as mean \pm standard deviation for continuous variables and as numerical counts and percentages for nominal variables. Hardy-Weinberg Equilibrium (HWE) deviation was tested by Pearson's Chi ${ }^{2}$ test. The $\mathrm{Chi}^{2}$ test was used to detect any association between the different genetic profiles (Fishers $2 \times 3$ Exact test when applicable). Risk was expressed as odds ratio (OR) and confidence interval (CI) level was set to $95 \%$. Normality testing of continuous variables was done using Kolmogorov Smirnov test. Independent samples $t$-test was used to investigate whether there was any significant difference between cases and controls in terms of continuous variables. One-way ANOVA and Kruskal-Wallis tests were used to detect the mean difference across the three genotypes within POAG group. A $p$ value less than 0.05 was considered statistically significant. All the analysis was done using SPSS version 22 (IBM Inc. Chicago, Ilinois, USA).

\section{Results}

No significant age and gender distribution was seen between POAG cases and controls. In addition, except for the family history of glaucoma $(p=0.012)$, systemic co-morbidities, smoking habit and glaucoma specific

Table 3 Effect of rs547984 genotypes on demographic and clinical characteristics within PAOG group

\begin{tabular}{|c|c|c|c|c|}
\hline \multirow[t]{2}{*}{ Characteristics } & \multicolumn{3}{|c|}{ Genotypes } & \multirow[t]{2}{*}{$p$ value } \\
\hline & $\overline{C / C}(n=20)$ No. $(\%)$ & $\mathrm{C} / \mathrm{A}(n=52)$ No. $(\%)$ & $\mathrm{A} / \mathrm{A}(n=18)$ No. $(\%)$ & \\
\hline \multicolumn{5}{|l|}{ DEMOGRAPHIC } \\
\hline Age in years, Mean (SD) & $58.6(13.8)$ & $61.5(12.1)$ & $60.5(11.6)$ & $0.674^{b}$ \\
\hline Male & $13(65.0)$ & $33(63.4)$ & $9(50.0)$ & 0.553 \\
\hline Female & $7(35.0)$ & $19(57.5)$ & $9(50.0)$ & - \\
\hline \multicolumn{5}{|l|}{ MEDICAL HISTORY } \\
\hline Family history of glaucoma & $4(20.0)$ & $9(17.3)$ & $1(5.5)$ & 0.408 \\
\hline Smoking & $10(50.0)$ & $18(34.6)$ & $6(33.3)$ & 0.440 \\
\hline Diabetes mellitus & $13(65.0)$ & $27(51.9)$ & $9(50.0)$ & 0.556 \\
\hline Hypertension & $9(45.0)$ & $28(53.8)$ & $10(55.5)$ & 0.758 \\
\hline Coronary artery disease & $2(10.0)$ & $4(76.9)$ & $0(0.0)$ & 0.421 \\
\hline Hypercholesterolemia & $5(25.0)$ & $9(17.3)$ & $0(0.0)$ & 0.091 \\
\hline \multicolumn{5}{|l|}{ GLAUCOMA INDICES } \\
\hline Intraocular pressure in $\mathrm{mmHg}$, mean (SD) & $33.9(6.1)$ & $35.2(8.3)$ & $31.3(5.7)$ & $0.206^{c}$ \\
\hline Cup/disc ratio & $0.69(0.19)$ & $0.74(0.16)$ & $0.65(0.23)$ & $0.285^{c}$ \\
\hline No. of anti-glaucoma medications & $2.8(0.6)$ & $2.8(0.8)$ & $2.4(0.6)$ & $0.065^{c}$ \\
\hline
\end{tabular}

${ }^{\mathrm{a}} \mathrm{Chi}{ }^{2}$ test, ${ }^{\mathrm{b}}$ One-way ANOVA, ${ }^{\mathrm{C}}$ Kruskal Wallis test 
Table 4 Effect of age, sex and genotype on disease outcome by binary logistic regression analysis

\begin{tabular}{lccc}
\hline Variables & Odds ratio & 95\% confidence interval & $p$ value \\
\hline Age & 1.02 & $0.99-1.04$ & 0.090 \\
Sex $^{\mathrm{a}}$ & 0.59 & $0.32-1.11$ & 0.101 \\
Genotype $^{\mathrm{b}}$ & - & - & 0.425 \\
C/A & 1.33 & $0.648-2.763$ & 0.431 \\
A/A & 0.84 & $0.355-1.982$ & 0.689 \\
\hline
\end{tabular}

${ }^{\mathrm{a}}$ Female as reference, ${ }^{\mathrm{b}} \mathrm{C} / \mathrm{C}$ as reference

clinical indices were found to be similar between the two study groups (Table 1 ).

The distribution of rs547984 polymorphism did not deviate significantly from the HWE $(p>0.05)$. Association analysis between cases and controls revealed no significant genotype distribution under additive $\left(\mathrm{Chi}^{2}=2.07, \mathrm{df}=2, p=0.356\right)$, dominant $(p=0.517)$ and recessive models $(p=0.309)$. Besides, the allele frequency distribution was also found to be non-significant $(\mathrm{OR}=1.08 ; 95 \% \mathrm{CI}=0.72-1.62 ; p=0.70)$. The minor "A" allele frequency was found to be 0.49 and 0.50 among POAG cases and controls, respectively (Table 2).

We further evaluated the effect of genotypes on different demographic and clinical variables in the POAG group. Age $(p=0.674)$ and gender $(p=0.553)$ were found to be non-significant. Similarly, family history, smoking and systemic diseases also showed no significant distribution. More importantly, specific clinical indices used to assess severity of glaucoma such as IOP, cup/disc ratio and number of anti-glaucoma medication too were found to be non-statistically significant between the genotype groups (Table 3 ).

In addition, to ascertain the effects of age, gender and genotype on the likelihood of having POAG a binary logistic regression analysis was performed. However, none of these factors could significantly explain the likelihood of POAG in this cohort (Table 4).

\section{Discussion}

This study investigated the association between SNP rs547984, which is in close proximity to ZP4 gene on chromosome 1q43, and POAG patients of Saudi origin.

Table 5 Comparison of rs547984 minor allele (A) frequency distribution among different ethnic group

\begin{tabular}{lcccc}
\hline Population & MAF $^{\text {a }}$ Controls & MAF POAG & $p$ value & Reference \\
\hline Japanese & 0.460 & 0.560 & 0.00033 & {$[4]$} \\
India & 0.363 & 0.417 & 0.437 & {$[6]$} \\
Afro-Caribbean & 0.305 & 0.317 & 0.657 & {$[7]$} \\
Korea & 0.484 & 0.540 & 0.093 & {$[9]$} \\
Saudi & 0.500 & 0.489 & 0.708 & This Study \\
\hline
\end{tabular}

${ }^{\mathrm{a}}$ Minor allele frequency
Previously this SNP was reported to be associated with POAG in a group of Japanese patients $(p=0.00006$, $\mathrm{OR}=1.34,95 \% \mathrm{CI}=1.16-1.54$ ) [4]. However, the authors did not offer any explanation on how SNP rs547984 contributes to POAG-pathogenesis. Subsequent studies have failed to establish a link between this SNP and POAG [6-8]. In our study, the genotype and allele frequencies detected in POAG patients were comparable to those in controls and thus were insignificant. This is similar to previous investigations which reported no association between this SNP and POAG or one of its clinical indices [6-8]. A comparison of minor allele frequency distribution in different population is shown in Table 5. A minor allele frequency of 0.50 in Saudi controls was comparatively similar to the Japanese (0.46) [8] and Korean (0.484) population [9], but higher than the Indian (0.363) [6] and Afro-Caribbean (0.305) [7] population.

Association analysis of the genotype effect on clinical parameters also did not provide any significant link. Smoking and other systemic diseases did not show any significant difference. More importantly, glaucoma specific indices such as IOP, cup/disc ratio and number of antiglaucoma medication also showed no statistically significant difference between genotype groups. Therefore, this SNP, independently or in relation to other clinical indices, does not have any effect on POAG development. However, the findings of this study require cautious interpretation since the study is limited by its sample size, performed in specific ethnicity and the role of other polymorphisms in this gene cannot be ruled out.

\section{Conclusion}

Our study was unable to replicate the previously reported association for variant rs547984 flanking the ZP4 gene with POAG and glaucoma specific indices such as IOP and cup/disc ratio indicating that this SNP is not a risk factor for POAG in the Saudi cohort. Furthermore, in the light of the present findings and the lack of association reported among other ethnic groups it appears that this polymorphism may not have a role in POAG development.

\section{Abbreviations}

Cl: Confidence interval; GWAS: Genome-wide association study; HWE: HardyWeinberg Equilibrium; IOP: Intraocular pressure; OR: Odds ratio;

POAG: Primary open angle glaucoma; SNP: Single nucleotide polymorphism; ZP4: Zona Pellucida Glycoprotein 4

\footnotetext{
Acknowledgments

The authors would like to thank the Glaucoma Research Chair at the Department of Ophthalmology, College of Medicine, King Saud University for suporting this study.

Funding

This work was supported by Glaucoma Research Chair at the Department of Ophthalmology, College of Medicine, King Saud University but had no role in the design of the study and collection, analysis, and interpretation of data and in writing the manuscript.
} 


\section{Availability of data and materials}

The data supporting the conclusions of this article are all presented within the article.

\section{Authors' contributions}

TAA: Performed experiments, results, manuscript draft preparation; NBE: performed genotyping experiments; AAK: statistical analysis, result interpretation, manuscript preparation; HK, FAA, SAA: subject recruitment, clinical examination, clinical data; SA, TS: sample collection and DNA extraction; KAA: study design, overall supervision, results, interpretation, and preparation of final version of the manuscript. All the authors have approved the final version of the manuscript.

\section{Competing interests}

Authors have no conflict of interests and the work was not supported or funded by any drug company. The paper has not been presented in any previous conference or scientific meeting.

\section{Consent for publication}

Not applicable.

\section{Ethics approval and consent to participate}

The study adhered to the tenets of the Declaration of Helsinki and had received approval from the Institutional Review Board and Research Ethics Committee. Written, informed consent was obtained from all participants prior to their inclusion in this study.

\section{Publisher's Note}

Springer Nature remains neutral with regard to jurisdictional claims in published maps and institutional affiliations.

\section{Author details}

'Glaucoma Research Chair, Department of Ophthalmology, College of Medicine, King Saud University, Riyadh 11411, Saudi Arabia. ${ }^{2}$ Case Western Reserve University, Ohio, USA. ${ }^{3}$ SAAD Research \& Development Center, Clinical Research Lab., SAAD Specialist Hospital, P.O. Box 30353, Al Khobar 31952, Saudi Arabia. ${ }^{4}$ Qassim University, Buraydah, Saudi Arabia. ${ }^{5}$ Department of Ophthalmology and Visual Sciences, University of Illinois at Chicago, Chicago, IL, USA. ${ }^{6}$ Ophthalmic Genetics Laboratory, Department of Ophthalmology, College of Medicine, King Saud University, P.O. Box 245, Riyadh 11411, Saudi Arabia.

Received: 26 December 2016 Accepted: 15 June 2017

Published online: 26 June 2017

\section{References}

1. Al Obeidan SA, Dewedar A, Osman EA, Mousa A. The profile of glaucoma in a tertiary ophthalmic University Center in Riyadh, Saudi Arabia. Saudi J Ophthalmol. 2011;25(4):373-9.

2. Janssen SF, Gorgels TG, Ramdas WD, Klaver CC, van Duijn CM, Jansonius $\mathrm{NM}$, et al. The vast complexity of primary open angle glaucoma: disease genes, risks, molecular mechanisms and pathobiology. Prog Retin Eye Res. 2013;37:31-67.

3. Abu-Amero K, Kondkar AA, Chalam KV. An updated review on the genetics of primary open Angle glaucoma. Int J Mol Sci. 2015;16(12):28886-911.

4. Nakano M, Ikeda Y, Taniguchi T, Yagi T, Fuwa M, Omi N, et al. Three susceptible loci associated with primary open-angle glaucoma identified by genome-wide association study in a Japanese population. Proc Natl Acad Sci U S A. 2009;106(31):12838-42.

5. Meczekalski B, Nawrot R, Nowak W, Czyzyk A, Kedzia H, Gozdzicka-Jozefiak A. Study on the zona pellucida 4 (ZP4) gene sequence and its expression in the ovaries of patients with polycystic ovary syndrome. J Endocrinol Investig. 2015;38(7):791-7.

6. Rao KN, Kaur I, Chakrabarti S. Lack of association of three primary open-angle glaucoma-susceptible loci with primary glaucomas in an Indian population. Proc Natl Acad Sci U S A. 2009;106(44):E125-6. author reply E127

7. Cao D, Jiao X, Liu X, Hennis A, Leske MC, Nemesure B, et al. CDKN2B polymorphism is associated with primary open-angle glaucoma (POAG) in the Afro-Caribbean population of Barbados, West Indies. PLoS One. 2012;7(6):e39278.
8. Takamoto M, Kaburaki T, Mabuchi A, Araie M, Amano S, Aihara M, et al. Common variants on chromosome 9p21 are associated with normal tension glaucoma. PLoS One. 2012;7(7):e40107.

9. Kim K, Heo DW, Kim S, Kim JS, Kim CS, Kang C. Expansive marker analysis replicating the association of glaucoma susceptibility with human chromosome loci 1q43 and 10p12.31. Eur J Hum Genet. 2014;22(3):409-13.

10. Abu-Amero KK, Kondkar AA, Mousa A, Osman EA, Al-Obeidan SA. Lack of association of SNP rs4236601 near CAV1 and CAV2 with POAG in a Saudi cohort. Mol Vis. 2012;18:1960-5.

11. Kondkar AA, Mousa A, Azad TA, Sultan T, Almobarak FA, Alawad A, et al. Analysis of polymorphism rs1900004 in atonal bHLH transcription factor 7 in Saudi patients with primary open Angle glaucoma. Genet Test Mol Biomarkers. 2016;20(11):715-8.

12. Abu-Amero KK, Kondkar AA, Mousa A, Almobarak FA, Alawad A, Altuwaijri S, et al. Analysis of Cyclin-dependent Kinase inhibitor-2B rs1063192 polymorphism in Saudi patients with primary open-Angle glaucoma. Genet Test Mol Biomarkers. 2016;20(10):637-41.

13. Kondkar AA, Mousa A, Azad TA, Sultan T, Alawad A, Altuwaijri S, et al. Polymorphism rs7555523 in transmembrane and coiled-coil domain 1 (TMCO1) is not a risk factor for primary open angle glaucoma in a Saudi cohort. J Negat Results Biomed. 2016;15(1):17.

14. Abu-Amero KK, Kondkar AA, Mousa A, Osman EA, Al-Obeidan SA. Association of Mn-SOD mutation (c.47T > C) with various POAG clinical indices. Ophthalmic Genet. 2014;35(2):85-90.

\section{Submit your next manuscript to BioMed Central and we will help you at every step:}

- We accept pre-submission inquiries

- Our selector tool helps you to find the most relevant journal

- We provide round the clock customer support

- Convenient online submission

- Thorough peer review

- Inclusion in PubMed and all major indexing services

- Maximum visibility for your research

Submit your manuscript at www.biomedcentral.com/submit
C Biomed Central 